\title{
Global or Adapted Advertising? Consumer Evaluation of Advertising Activity of Foreign Enterprises on the Polish Market
}

\author{
Robert Nowacki
}

ABSTRACT Intensification of globalization processes in the contemporary world entails conse-quences for all areas of socio-economic life. The latter concerns also advertising, which is particularly sensitive to the developments occurring in the global envi-ronment. Expansion into foreign markets presents enterprises with the dilemma of how to advertise their products and services. The specific question which appears in this context is whether to use standardized or adapted advertising. The attitude of the audience on the target market is of key importance. The present article also focuses on the impact of globalization on the recipients' perception of the adver-tising activity of foreign companies operating in the Polish market. Assessment of the degree of acceptance of foreign enterprises' standardized advertising activities on the Polish market, their attractiveness and impact on competitiveness, from the perspective of Polish consumers. The basis for the study are the findings of a sur-vey conducted in 2019 and 2020 on a sample of Polish consumers aged $15+$ se-lected using the quota method. The subject of the research were opinions on advertising activities used on the Polish market by foreign companies, taking into account the differentiation into global and adapted advertising. The respondents assessed the level of attractiveness and acceptance of activities related to advertis-ing standardization procedures. The results of the research indicate that Polish consumers perceive the globalization of advertising and have mixed feelings about it. On the one hand, they appreciate the attractiveness of standardized advertise-ments, on the other, they assess their effectiveness as worse. However, the re-spondents also point out that they have a positive impact on the competitiveness of foreign companies. The perception of standardized advertising is generally not dependent on demographic characteristics. There is only a slight direct effect of age on the perception of attractiveness and effectiveness of standardized and adapted advertising.

KEY WORDS: $\quad$ Advertising, advertising perception, global and adapted advertising, foreign enterprises, attractiveness and competitiveness of advertising.

JEL Classification: M37, M21.

University of Economics and Human Sciences in Warsaw

\section{Introduction}

The development of globalization processes entails several conse-quences for all spheres of the modern world. It is important to note that the paradigms related to marketing are also reorienting. Moreover, it may be stated that a new concept of looking at the phenomena of $\underline{\underline{0}}$ competition and creating a marketing strategy is formed.

Correspondence concerning this article should be addressed to:

Robert Nowacki, University of Economics and Human Sciences in Warsaw, Poland ul. Okopowa 59, 01-043 Warsaw, Poland.

E-mail: r.nowacki@vizja.pl
As a result of the changes taking place in terms of the activities of enterprises, the evolution of the concept of marketing on foreign mar-kets becomes apparent. A phenomenon that is noticed more and more frequently is the interpenetration, convergence or even unification of cultural variables. All the above factors lead to distinguishing the last of the marketing concepts, which T. Levitt referred to as global market-ing (Levitt, 1986). The term relates to the activities of the world's largest corporations operating on a global scale, not 
necessarily in a com-pletely unified manner. Their operations are oriented towards the de-velopment of marketing standardization processes, based on the as-sumption that the buyers of the product in different countries are large-ly the same, namely, they have unified needs, expectations, prefer-ences, and they present a similar behavior model (Keegan \& Green, 2000). As a consequence of the abovesaid evolution, the conditions which are created allow for undertaking standardization activities at the level of all marketing instruments, including advertising.

At present, advertising as the driving force of free competition is seen as a key factor of economic growth (Arens et al., 2009), consid-ered from various perspectives and analyzed in terms of its marketing, communication, economic, social, cultural, and even religious and po-litical dimensions (Sanayei et al., 2012). Its effectiveness is determined by the use of effective communication, defined through the prism of the processes of transmitting, receiving, and processing information (Clow \& Baack, 2010), which refers to the exchange of information, ideas and shaping the relationship between the sender and the recipient (Belch \& Belch, 2009).

In the field of advertising, the impact of globalization is expressed in determining the relationship between the possibility of standardization (globalization) and the need for adaptation of communications. These appear to be the two main trends in advertising on foreign mar-kets (Melewar \& Vemmervik, 2004; Papavassiliou \& Stathakopoulos, 1997; Schmidt, 2016). Choosing one of them is crucial for the effec-tiveness of advertising activities. Adapting to the requirements and expectations of the recipients of advertising constitutes the basis for corporate initiatives (Harvey, 1993). The process of perceiving advertising messages is one of the key determinants of consumer behavior (de Mooij, 2003; 2004; 2010; de Mooij \& Hofstede, 2002).

In Poland, little research has been carried out on this issue, despite the fact that the advertising market has been developing dynamically for the last 30 years. This study, therefore, sets out to investigate the research problem and answer the question of how Polish consumers perceive the advertising activities of foreign companies.

The objective of the article is to assess the degree of acceptance of standardized advertising activities carried out on the Polish market by foreign companies, their attractiveness and effectiveness, and their impact on competitiveness from the perspective of Polish consumers.

The basis for the considerations is the findings of the research con-ducted in 2019-2020 using the CAWI method on a sample of 1201 Polish consumers aged 15 and above, selected using the quota meth-odology. The aim of the research project has been to examine the re-spondents' opinions on advertising activities and strategies applied on the Polish market by foreign companies, taking into account the differ-entiation between global and adapted advertising. The survey partici-pants assessed various aspects of advertising activities, including the acceptance and effectiveness of global advertising. The analysis of the results takes into account the relationship between the examined issues and basic demographic characteristics (gender and age) as well as the model of the relationship between the perception of attractiveness and effectiveness in the context of the respondents' age.

The first part of the article presents the background for considera-tions relating to the impact of the globalization phenomenon on the advertising activities of enterprises. In particular, reference was made to the issue of standardization and adaptation of advertising as two different advertising strategies. The next section provides a detailed description of the research method, the method of data collection, the sample of respondents as well as the tools and calculation procedures used. The next section contains the most important findings of the study presented in a descriptive and tabular manner. Subsequently, the results were discussed, together with conclusions and comments con-cerning the limitations of the present study and recommendations for further research.

\section{Literature Review}

Standardization of advertising is defined as the use of a uniform approach to advertising activities in differ- 
ent countries, based on the same advertising message of the same product promoted abroad (Backhaus et al., 2001; Nelson \& Paek, 2007; Papavassiliou \& Stathakopoulos, 1997), with a possible translation of the content of the advertisement into a local language (Harvey, 1993; Onkvisit \& Shaw 1990). Standardization of advertising ensures a consistent image of the brand worldwide (Kirpilani et al., 1988; Onkvisit \& Shaw, 1990; Tai, 1997; Melewar et al., 2000), consistent global positioning (Shoham, 1995), the application of strategies and solutions which already proved successful in other countries or effective use of the advertising budget (Kanso, 1992; Kirpilani et al., 1988; Jain, 1989; Levitt, 1983; Nowacki, 2007a; Tai, 1997;).

Adaptation is an alternative approach to international advertising. It is defined as the use of different advertising messages in different markets (Wang \& Yang, 2011). The purpose of adaptation is to obtain a differential advantage by adjusting advertising to achieve maximum effectiveness of sales (Onkvisit \& Shaw, 1990). The adaptation of advertising is usually associated with the decentralization of advertising efforts. The advantage of this solution is the ability to adapt it to the local culture, infrastructure and competition in a given country. The visual and verbal adaptation of an advertisement increases the likeli-hood that the advertisement will be effective. Other reasons for adapta-tion include the accuracy of positioning and price discrimination (Sho-ham, 1995; 1999).

The decision to standardize or adapt advertisements is not dichoto-mous. Rather, international firms choose between two extremes: full standardization and adaptation (Harris, 1994). Papavassiliou and Stathakopoulos (1997) have suggested that international advertising decisions can be viewed as a continuum with two polar ends, which are, as mentioned above, standardization and adaptation of advertising strategy. The latter was confirmed by research conducted, among oth-ers, by Whitelock and Chung (1989), Mueller (1991), Seitz and Johar (1993), and Harris and Attour (2003). The studies show that standardi-zation and advertising procedures are a widely used practice, but total standardization is the exception rather than the rule (Harris \& Attour, 2003), even for the largest corporations (Kanso \& Nelson, 2002). The concept "Think globally, act locally" is becoming more and more common; and global companies implement and adopt global trends, services, values and products to local cultural and social conditions in line with this principle (Menon, 2014). This tendency is also reflected in the field of various communication activities, including advertising messages (Moon \& Jain, 2002), as an expression of a critical analysis of the positive and negative aspects of standardization and adaptation (Zou et. al., 1997).

The degree of standardization of advertising activities, therefore, depends on many factors, which Harvey (1993) divides into three groups: factors affecting the company that advertises a product or ser-vice (variables characterizing the product, market competition and the organization itself), factors determining the process of creating and broadcasting an advertising message (variables related to infrastructural and legal conditionings) and factors influencing consumers who are recipients of advertising communications (socio-cultural variables). The necessary condition is the susceptibility of the product/services offer to the globalization of advertising (Kotler, 1997; Belch \& Belch, 2009).

Taking into consideration the diversity of the cultural environment of the sender and recipient of the message appears to be of key im-portance in the process of making decisions regarding standardization or adaptation (Toyne \& Walters, 2004). In relation to advertising, cul-ture should be defined as the learned lifestyle of a particular society, their interpersonal contacts and reacting to environmental stimuli (including advertising stimuli). It consists of the general values for a given society, accumulated by tradition, extended and enhanced by language, art, aesthetics, customs, morality, determining the guidelines for peo-ple's behavior and the way they perceive the world (Hanna \& Wozni-ak, 2001). Relationships and interdependencies between the features of the national culture, described by G. Hofstede as "programming of the mind" (Hofstede, 2011) and consumer behavior allow for the proper adjustment of the marketing strategy to the needs and expecta-tions of buyers, which, in turn, often determines the success of a brand or enterprise on the market. The elements of culture that can be ana-lyzed in the context of purchasing decisions or the impact of advertis-ing include adopted code of conduct, assumptions, and stereotypes, norms, and values as well as the way of perceiving, adopting, 
and as-sessing values, adopted methods and means of communicating adver-tising messages (de Mooij \& Hofstede, 2010). Advertising messages developed within one culture may be misunderstood or largely ineffec-tive in another culture due to different attitudes or different percep-tions of messages (de Mooij, 2015). The coding and decoding of the message are strongly conditioned by culture - cultural heritage, assumptions, stereotypes, and prejudices may constitute significant barri-ers to communication (Lunenburg, 2010), influencing the evaluation of attractiveness and, consequently, the effectiveness of advertising. The concept of adapting advertising activities to the cultural specificity of the target market has become increasingly important in recent times, which is confirmed by numerous studies (Boddewyn et. al., 1986; Hite \& Frazer, 1988; Kanso, 1992). Cultural mismatch of such messages is mentioned, related to, inter alia, the ethnocentrism of consumers, a negative attitude towards solutions derived from other countries. All these factors are conducive to the adaptation of advertising (Mueller, 1992; Synodinos et. al., 1989). The perception of advertising is condi-tioned by the ethnocentric attitude of consumers, which is expressed in a greater tendency to accept the content which is seen as closer to the recipient and their cultural circle and consequent shaping of posi-tive emotional and behavioral reactions towards the advertised product (perception, attitude towards the brand, intention to buy) (Burke \& Edell, 1989; MacKenzie \& Lutz, 1989; Nowacki, 2008; Park \& Young, 1986).

\section{Research Method}

The issue of perception and evaluation of advertising activities in the context of globalization has been the subject of research conducted at the turn of 2019 and 2020. The study was carried out with the appli-cation of a CAWI (Computer Assisted Web Interview) method examin-ing 1201 Polish individuals over 15 years of age, selected as representatives of the Polish population in terms of gender, age and place of residence (provinces). The sample was selected using a quota method. The study included $52.4 \%$ women and $47.6 \%$ men. $18.7 \%$ of the re-spondents were aged $15-24,18.9 \%$ - aged $25-34$, $17.9 \%$ - aged $35-44,18.1 \%$ - aged $45-54$, and $26.4 \%$ - over the age of 54 .
The analysis was carried out using the author's original question-naire, containing, among others, questions concerning the perception of globalization as a process shaping advertising as well as the percep-tion and evaluation of advertising activities carried out by foreign companies operating on the Polish market against the background of the activities of domestic firms. In particular, the article has examined the following research problems. The first examined issue concerned the opinion regarding the need to adapt advertising messages to the cultural specificity of the country in which the advertisement is broad-cast, expressed using an alternative nominal scale (it does not have to be adjusted - it should be adjusted). The second issue concerned the question of evaluating the effectiveness of global advertising carried out with the use of an ordinal scale (rating the effectiveness as high - medium - low). The third issue was related to the evaluation of global advertising from the point of view of seven parameters, assessed on a threepoint ordinal scale (the ratings of high - medium - low lev-els). The last issue concerned a comparative analysis of the relation-ship between the attractiveness and effectiveness of global and adapted advertising, assessed from the perspective of seven-factor (in the case of attractiveness) and six-factor loadings (in the case of effectiveness, assessed on a nominal scale: yes-no).

The following system of factor loadings was adopted in the analysis:

Attractiveness of advertising:

- A1 Interesting

- A2 Engaging

- A3 Relaxing

- A4 Appealing

- A5 Professionally made

- A6 Liked

- A7 Original

Effectiveness of advertising:

- S1 Encouraging to buy

- S2 Informative

- S3 Reliable

- S4 Inspiring confidence

- S5 Affecting the purchase

- S6 Teaching new behaviors

The results of the conducted analyses will serve to verify the fol-lowing hypotheses:

- H1: Despite being aware of the globalization of advertising, Polish consumers do not accept its standard- 
ization and expect foreign companies to adjust it to the specifics of the target market, although at the same time they are convinced of its effectiveness.

- H1a: Polish consumers accept the standardization of advertising only to a limited degree and expect foreign companies to adjust it to the specificity of the target market.

- H1b: Polish consumers evaluate the effectiveness of standardized advertising positively.

- H1c: Polish consumers value the attractiveness of standardized advertising more than its effectiveness.

- H2: Demographic features of Polish consumers do not differentiate the perception and acceptance of the phenomenon of advertising globalization and its standardization.

- H2a: Gender and age of Polish consumers do not significantly dif-ferentiate the perception of the need to adapt advertising to the specificity of the target market.

- H2b: Gender and age of Polish consumers do not significantly dif-ferentiate the assessment of the effectiveness of standardized ad-vertising.

- H2c: There are no statistically significant differences in the percep-tion of the attractiveness and effectiveness of standardized adver-tising depending on the gender and age of Polish consumers.

- H3: There is a statistically significant relationship between age and the perception of attractiveness and effectiveness of standardized and adapted advertising.

- H3a: There is a direct influence of age on the perception of the attractiveness of standardized and adapted advertising.

- H3b: There is a direct influence of age on the perception of the effectiveness of standardized and adapted advertising.

- H3c: There is a direct influence of the perception of attractiveness on the perception of the effectiveness of standardized and adapted advertising.

- H3d: There is an indirect influence of age on the perception of the effectiveness of standardized and adapted advertising.

The results were processed with the use of the IBM SPSS 27.0 sta-tistical package. The analysis used statistically significant indicators of the structure (percentages), measures of central tendency (weighted average) and measures of correlation between the variables. The rela-tionships between the independent (explanatory) and dependent (re-sponding) variables were determined based on the non-parametric chi-square test, and the strength using the Cramér's V coefficient.

In the case of the first three problems, the results of the analyses were presented taking into account the differentiation into the basic demographic categories (gender and age). The relationship between the independent variable (explanatory) and the dependent (responding) variable was determined by the non-parametric chi-squared test, Mann-Whitney U tests (in the case of explanatory variable concerning gen-der) and the Kruskal-Wallis test (for the variables related to age), and the strength of the identified relationships was determined using the Cramér's $\mathrm{V}$ coefficient.

To verify the relationships between the analyzed variables indicated in the fifth examined research problem, the author applied the technique of modelling structural equations with the application of the partial least square method (PLS-SEM) using the SmartPLS 3 pro-gram. PLS-SEM represents a wellsubstantiated method for estimating complex causeeffect-relationship models in management research (Gudergan et al., 2008).

The reliability of the variables was tested using Cronbach's alpha and composite reliability (CR) methods. The authors assumed that the factor loadings need to be larger than 0.6 , indicating that more than $50 \%$ of the variance in a single parameter can be explained by the cor-responding latent variable (Latif et al., 2020). In turn, the Average Var-iance Extracted (AVE) should be greater than 0.50. An AVE value of 0.50 and more indicates a sufficient degree of convergent validity, which means that the latent variable explains more than half of the variance of its indicators (Hair et al., 2011).

\section{Results and Discussion}

The analysis of the survey results shows that the respondents are convinced of the need to adapt advertising to the specificity of the country in which it is used. This view is shared by $73.0 \%$ of respond-ents. Women express this opinion more often, however, there occurs only a slight difference in terms of the responses 
between genders. Analysis with the application of a chi-squared test indicated a statisti-cally significant relation at the level of $\mathrm{p}=0.05$ in the case of independent variable related to gender $\left(\chi^{2}\right.$ test value amounted to 5.078 with $\mathrm{df}=1$, and a critical significance level $\mathrm{p}=0.024)$. However, the strength of the relationship was very small - the coefficients of Cramér's V reached the value of 0.065 ; in the case of the second independent var-iable, age, the differentiation of responses turned out to be statistically insignificant. The $\chi^{2}$ test value amounted to 5.078 with $\mathrm{df}=4$ and the critical significance level $\mathrm{p}=0.095$ (Table 1 ).

The respondents recognize the importance of global advertising in the process of shaping the competitiveness of companies using it. $41.3 \%$ assess its effectiveness as high, $42.4 \%$ as average, and only $16.3 \%$ evaluate it as low. The high effectiveness is indicated slightly more often by men and generally younger people, although the relationships are not statistically significant. The Mann-Whitney $\mathrm{U}$ test (in the case of gender) and the Kruskal-Wallis test (in the case of age) do not give grounds to adopt the hypotheses concerning the relations between the variables - the critical level of significance for both tests exceed the assumed level of $\mathrm{p}=0.05$ (Table 2).

From the point of view of individual parameters characterizing global advertising, the respondents rated its originality/creativity and attractiveness at the highest levels. These factors received the average scores on a three-point scale, where 1 was the highest and 3 the lowest, and they amounted to 1.76 and 1.78 , respectively. The remaining parameters obtained average scores in the range of 1.90-2.00, that is, above or equal to the average. The lowest rating was obtained in relation to the content of advertising. In both correlation cross-sections, the differences

\section{Table 1}

Opinion on the Need to Adapt the Advertisement to the Specific Characteristics of the Country in Which it is Used

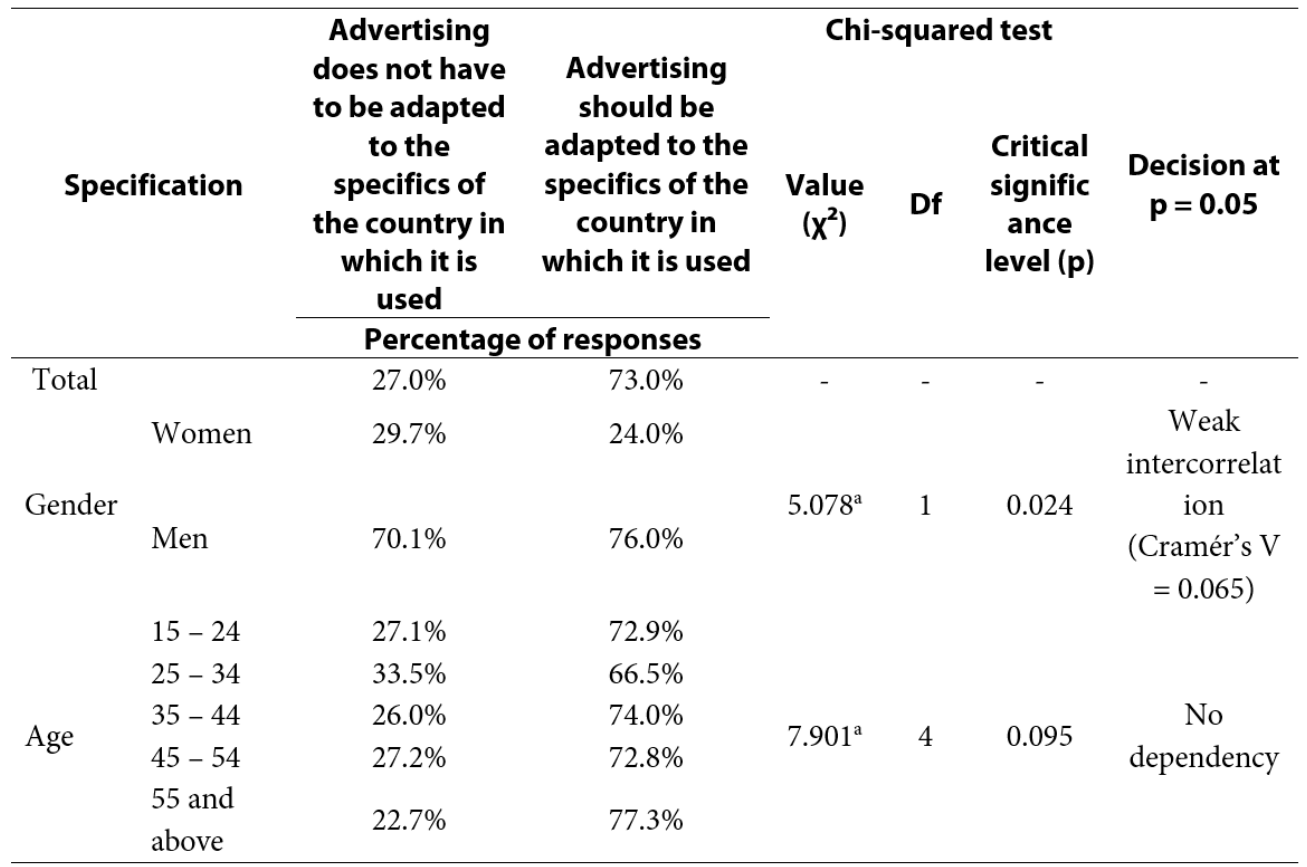

Note: ${ }^{\mathrm{a}} 0.0 \%$ cells have an expected value of less than 5 . 
between the scores were small, although it is worth noting that women in six cases (apart from matching their expectations) tended to assign higher scores than men (Table 3).

Slight differences in the assessments from the point of view of demographic characteristics of the respondents were confirmed in the analysis with the use of dependency tests. In the case of the study of the relationship between gender and individual assessments, a statistically significant relationship occurred only in the case of the parameters: adaptation to the expectations of others, content, and readability/comprehensibility. Higher scores were assigned by women. The critical significance values of the MannWhitney $U$ test did not exceed the adopted threshold value of $\mathrm{p}=0.05$. In all three cases, however, the relationship was very weak (the value of the Cramer's $\mathrm{V}$ coefficient amounted to max. 0.102). In the case of the relationship between the age of the respondents and the analyzed characteristics of global advertising, the author was able to discover a relationship only in the case of attractiveness and originality/creativity of advertising. In this case, higher ratings were assigned by representatives of younger age groups. In the case of these two features, the strength of correlation was also small, the Cramer's V-coefficient was estimated at the level of 0.090 and 0.112 (Table 4).

The last aspect of the analysis was a comparative analysis of the relationship between the attractiveness and effectiveness of global and adapted advertising. The results of reliability and validity with the factor loadings are presented in Table 5. The reliability of the variables was examined using Cronbach's alpha and composite reliability (CR) methodology. As initially assumed, factor loadings are greater than 0.6. The value of the factor loadings ranges from

Table 2

Opinion on the Effectiveness of Global Advertising in Shaping the Competitiveness of Foreign Companies

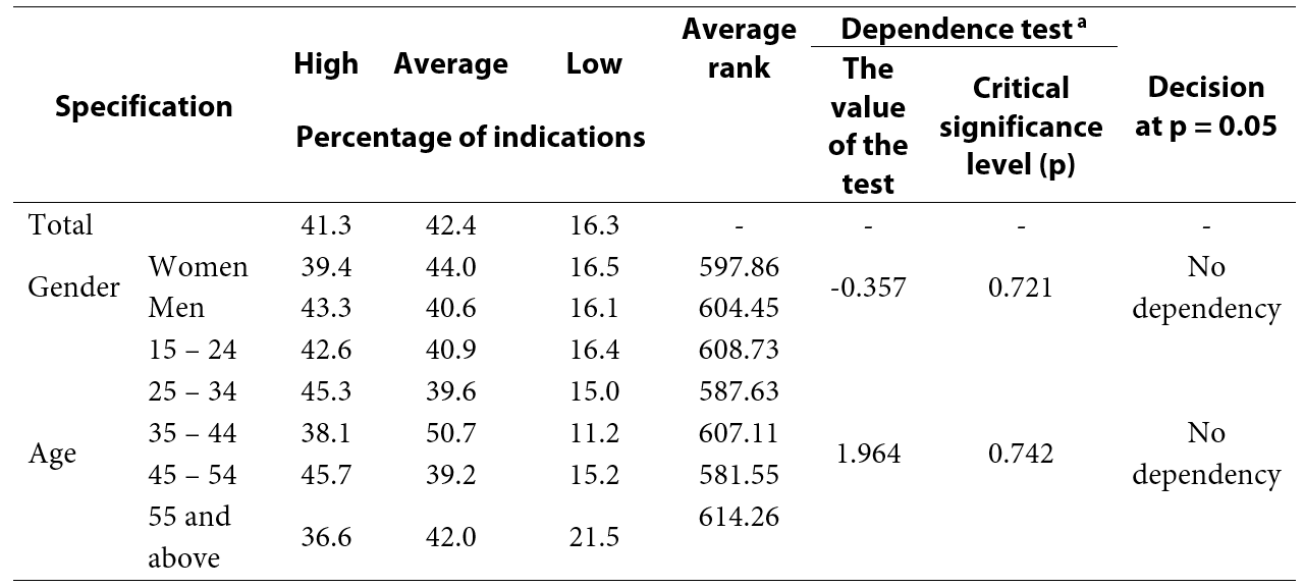

Note: ${ }^{a}$ The Mann-Whitney U test for independent variable of gender or Kruskal-Wallis test for independent variable of age. 
Table 3

Asessment of Individual Parameters of Global Advertising

\begin{tabular}{|c|c|c|c|c|c|c|c|c|c|}
\hline & Specification & & 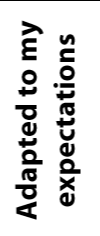 & 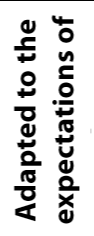 & 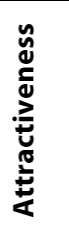 & 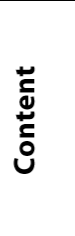 & 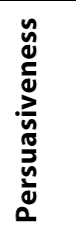 & 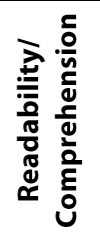 & 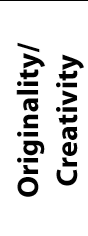 \\
\hline \multirow{2}{*}{ Total } & & Mean & 1.90 & 1.91 & 1.78 & 2.00 & 1.93 & 1.94 & 1.76 \\
\hline & & SD & .584 & .557 & .645 & .628 & .688 & .629 & .646 \\
\hline \multirow{4}{*}{ Gender } & \multirow{2}{*}{ Women } & Mean & 1.91 & 1.87 & 1.75 & 1.94 & 1.91 & 1.90 & 1.74 \\
\hline & & SD & .572 & .551 & .647 & .610 & .678 & .640 & .652 \\
\hline & \multirow{2}{*}{ Men } & Mean & 1.88 & 1.95 & 1.81 & 2.06 & 1.96 & 1.99 & 1.77 \\
\hline & & SD & .596 & .562 & .642 & .641 & .698 & .614 & .640 \\
\hline \multirow{10}{*}{ Age } & \multirow{2}{*}{$15-24$} & Mean & 1.88 & 1.87 & 1.65 & 1.99 & 1.89 & 2.03 & 1.66 \\
\hline & & SD & .563 & .575 & .631 & .601 & .642 & 619 & .663 \\
\hline & \multirow{2}{*}{$25-34$} & Mean & 1.83 & 1.92 & 1.73 & 2.07 & 1.89 & 1.94 & 1.73 \\
\hline & & SD & .533 & .538 & .635 & .595 & .709 & .649 & .640 \\
\hline & \multirow{2}{*}{$35-44$} & Mean & 1.96 & 1.92 & 1.85 & 2.00 & 2.01 & 1.92 & 1.75 \\
\hline & & SD & .610 & .545 & .663 & .666 & .749 & .640 & .712 \\
\hline & \multirow{2}{*}{$45-54$} & Mean & 1.92 & 1.92 & 1.82 & 2.01 & 2.00 & 1.92 & 1.81 \\
\hline & & SD & .611 & .560 & .671 & .694 & .748 & .644 & .650 \\
\hline & \multirow{2}{*}{55 and above } & Mean & 1.91 & 1.91 & 1.83 & 1.96 & 1.90 & 1.91 & 1.81 \\
\hline & & SD & .593 & .567 & .620 & .594 & .610 & .602 & .583 \\
\hline
\end{tabular}

0.602 (A1) to 0.810 (A7) for adapted advertising and between 0.627 (A1) and 0.805 (A7) for standardized advertising. The isolated variance (AVE) also meets the assumed conditions, as it exceeds 0.50 . In the case of adapted advertising, it reaches the level of 0.517 (for the variable related to attractiveness) and 0.513 (for the variable connected with effectiveness), and in the case of standardized advertising, it amounts to 0.878 and 0.850 , respectively. The last column includes the values of the variance inflation coefficient - the estimates range from 1.269 to 2.268 . However, the values close to 1 indicate at most a slight collinearity between factor loadings.

The next stage of the study focused on the assessment of discriminant validity. Cross-loading aims to answer the following question: does any indicator correlate more strongly with the other constructs than with its own construct? (Kock, 2015). The study shows that all factor-loadings are greater than their cross-loadings. Table 6 presents the results of discriminant validity using the criterion by the Heterotrait-Monotrait Method (HTMT). HTMT values close to 1 indicate a lack of discriminant validity (Henseler et al., 2015). The 0.90 value can be interpreted as an upper boundary of acceptable construct correlations (Franke \& Sarstedt, 2019). In the case of the presented results, all values meet this criterion.

After assessing the discriminant validity, the hypotheses regarding the relationship between the variables concerning age, attractiveness and effectiveness of adapted and standardized advertising have been verified (Table 7). In this case, it can be concluded that all relationships are statistically significant $(\mathrm{p}<$ 0.05). One may observe a differentiation of relationships in the case of adapted and standardized advertising. As age increases, the opinion about the attractiveness and effectiveness of adapted advertising is higher, and the opinion about the attractiveness and 


\section{Table 4}

Comparison of the Values of the Mann-Whitney U Test and the Kruskal-Wallis Test Verifying the Relationship Between the Parameters of Global Advertising and the Gender and Age of the Respondents

\begin{tabular}{|c|c|c|c|c|c|c|c|c|}
\hline \multicolumn{2}{|c|}{ Specification } & 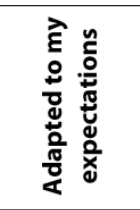 & 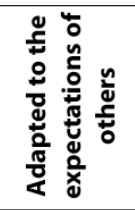 & 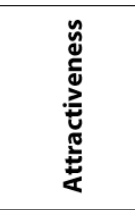 & 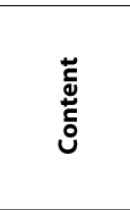 & 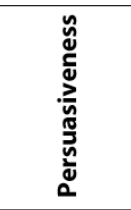 & 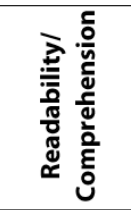 & 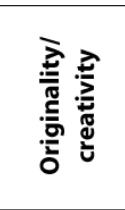 \\
\hline \multirow{3}{*}{\multicolumn{2}{|c|}{$\begin{array}{l}\text { Women } \\
\text { Men }\end{array}$}} & 608,88 & 852,63 & 585,88 & 573,81 & 589,87 & 580,13 & 592,18 \\
\hline & & & & 617,63 & 630,90 & 613,24 & 623,94 & \\
\hline & & 592,33 & 621,20 & & & & & 610,70 \\
\hline \multicolumn{2}{|c|}{$\begin{array}{l}\text { The value of Mann- } \\
\text { Whitney U test }\end{array}$} & -0.978 & -2.344 & -1.766 & -3.264 & -1.281 & -2.498 & -1.028 \\
\hline \multicolumn{2}{|c|}{$\begin{array}{l}\text { Critical significance } \\
\text { level (p) }\end{array}$} & 0.328 & 0.019 & 0.077 & 0.001 & 0.200 & 0.012 & 0.304 \\
\hline \multicolumn{2}{|c|}{ Decision at $\mathrm{p}=0.05$} & $\begin{array}{c}\text { No } \\
\text { dependency }\end{array}$ & $\begin{array}{c}\text { Weak } \\
\text { association } \\
\text { (Cramér's V } \\
=0,070)\end{array}$ & $\begin{array}{c}\text { No } \\
\text { dependency }\end{array}$ & $\begin{array}{c}\text { Weak } \\
\text { association } \\
\text { (Cramér's V } \\
=0,102)\end{array}$ & $\begin{array}{c}\text { No } \\
\text { dependency }\end{array}$ & $\begin{array}{c}\text { Weak } \\
\text { association } \\
\text { (Cramér's V } \\
=0,080 \text { ) }\end{array}$ & $\begin{array}{c}\text { No } \\
\text { dependency }\end{array}$ \\
\hline \multirow{5}{*}{ Age } & $15-24$ & 594.32 & 579.58 & 538.02 & 594.98 & 582.14 & 642.54 & 552.68 \\
\hline & $25-34$ & 566.95 & 606.06 & 576.90 & 633.28 & 582.81 & 599.34 & 589.45 \\
\hline & $35-44$ & 631.82 & 608.20 & 633.04 & 599.15 & 634.45 & 591.14 & 591.09 \\
\hline & $45-54$ & 608.99 & 608.13 & 621.82 & 605.82 & 628.10 & 591.39 & 627.69 \\
\hline & $\begin{array}{l}55 \text { and } \\
\text { above }\end{array}$ & 603.75 & 602.81 & 626.97 & 580.11 & 586.17 & 585.97 & 632.01 \\
\hline \multicolumn{2}{|c|}{$\begin{array}{l}\text { The value of the } \\
\text { Kruskal-Wallis test }\end{array}$} & 5.758 & 1.632 & 16.043 & 4.241 & 6.271 & 5.442 & 10.652 \\
\hline \multicolumn{2}{|c|}{$\begin{array}{l}\text { Critical significance } \\
\text { level (p) }\end{array}$} & 0.218 & 0.803 & 0.003 & 0.374 & 0.180 & 0.245 & 0.031 \\
\hline \multicolumn{2}{|c|}{ Decision at $\mathrm{p}=0.05$} & $\begin{array}{c}\text { No } \\
\text { dependency }\end{array}$ & $\begin{array}{c}\text { No } \\
\text { dependency }\end{array}$ & $\begin{array}{c}\text { Weak } \\
\text { association } \\
\text { (Cramér's V } \\
=0,090 \text { ) }\end{array}$ & $\begin{array}{c}\text { No } \\
\text { dependency }\end{array}$ & $\begin{array}{c}\text { No } \\
\text { dependency }\end{array}$ & $\begin{array}{c}\text { No } \\
\text { dependency }\end{array}$ & $\begin{array}{c}\text { Weak } \\
\text { association } \\
\text { (Cramér's V } \\
=0,112)\end{array}$ \\
\hline
\end{tabular}

effectiveness of standardized advertising tends to be lower. The higher the perceived attractiveness of an advertisement, the more often respondents indicate its effectiveness - this applies to both types of advertising activities analyzed in the research.

The presented analyses allow verifying the hypotheses. The vast majority of consumers share the opinion that advertising needs to be adapted to the specific characteristics of the target market. This is evidenced by the answers to the first question included in the survey. This allows for the adoption of the H1a hypothesis. At the same time, the distribution of responses given to the second question also allows the author to adopt the H1b hypothesis - more than half of the respondents note a positive impact of stan- dardized advertising on shaping competitiveness. On the other hand, based on the third question, the H1c hypothesis may be adopted, because the average ratings for the attractiveness of standardized advertising are higher than the ratings assigned for the effectiveness of impact on the recipient. Adopting the Hla, $\mathrm{H} 1 \mathrm{~b}$ and $\mathrm{H} 1 \mathrm{c}$ hypotheses also supports the adoption of the $\mathrm{H} 1$ hypothesis.

Most of the findings show no or very weak correlation between the demographic characteristics of the respondents and the perception of standardized and adapted advertising. This confirms the hypotheses $\mathrm{H} 2 \mathrm{a}, \mathrm{H} 2 \mathrm{~b}, \mathrm{H} 2 \mathrm{c}$, and thus also the hypothesis $\mathrm{H} 2$, which is the result of the three partial hypotheses being supported. 
Table 5

Item Loading, Reliability and Validity

\begin{tabular}{|c|c|c|c|c|c|c|c|c|c|c|}
\hline \multirow{2}{*}{ Factor loadings } & \multicolumn{5}{|c|}{ Adapted advertising } & \multicolumn{5}{|c|}{ Standardized advertising } \\
\hline & $\lambda$ & Alpha & CR & AVE & VIF & $\lambda$ & Alpha & CR & AVE & VIF \\
\hline \multicolumn{11}{|c|}{ Attractiveness } \\
\hline A1 Professionally made & 0.602 & \multirow{8}{*}{0.843} & & & 1.430 & 0.627 & \multirow{7}{*}{0.838} & \multirow{7}{*}{0.846} & \multirow{7}{*}{0.878} & 1.506 \\
\hline A2 Liked & 0.714 & & & & 1.515 & 0.688 & & & & 1.439 \\
\hline A3 Engaging & 0.755 & & & & 1.862 & 0.765 & & & & 1.867 \\
\hline A4 Original & 0.677 & & 0.881 & 0.517 & 1.449 & 0.667 & & & & 1.433 \\
\hline A5 Relaxing & 0.708 & & & & 1.562 & 0.689 & & & & 1.517 \\
\hline A6 Appealing & 0.748 & & & & 1.816 & 0.735 & & & & 1.812 \\
\hline A7 Interesting & 0.810 & & & & 2.203 & 0.805 & & & & 2.128 \\
\hline \multicolumn{10}{|c|}{ Effectiveness } & \\
\hline S1 Reliable & 0.786 & \multirow{6}{*}{0.809} & \multirow{6}{*}{0.863} & \multirow{6}{*}{0.513} & 2.089 & 0.762 & \multirow{6}{*}{0.783} & \multirow{6}{*}{0.788} & \multirow{6}{*}{0.850} & 1.804 \\
\hline S2 Inspiring confidence & 0.768 & & & & 2.268 & 0.760 & & & & 2.057 \\
\hline S3 Affecting the purchase & 0.725 & & & & 1.797 & 0.704 & & & & 1.652 \\
\hline S4 Teaching new behaviors & 0.607 & & & & 1.269 & 0.699 & & & & 1.456 \\
\hline S5 Encouraging to buy & 0.680 & & & & 1.352 & 0.713 & & & & 1.302 \\
\hline S6 Informative & 0.718 & & & & 1.490 & 0.703 & & & & 1.369 \\
\hline
\end{tabular}

Table 6

Discriminant Validity Using HTMT Criterion

\begin{tabular}{|c|c|c|c|c|c|c|}
\hline & \multicolumn{3}{|c|}{ Adapted advertising } & \multicolumn{3}{|c|}{ Standardized advertising } \\
\hline & Age & Attractiveness & Effectiveness & Age & Attractiveness & Effectiveness \\
\hline \multicolumn{7}{|l|}{ Age } \\
\hline Attractiveness & $\begin{array}{c}0.12 \\
1\end{array}$ & & & 0.182 & & \\
\hline Effectiveness & $\begin{array}{c}0.13 \\
4\end{array}$ & 0.855 & & 0.206 & 0.808 & \\
\hline
\end{tabular}

Table 7

Direct Relations (Hypotheses H3a-c) and Mediation Analysis (Hypotheses H3d)

\begin{tabular}{lcccccc}
\hline & \multicolumn{3}{c}{ Adapted advertising } & \multicolumn{3}{c}{ Standardized advertising } \\
& $\boldsymbol{\beta}$ & $\mathbf{t}$ & $\mathbf{p}$ & $\boldsymbol{\beta}$ & $\mathbf{t}$ & $\mathbf{p}$ \\
\hline $\mathrm{H} 3 \mathrm{a}:$ age $\rightarrow$ attractiveness & 0.110 & 3.966 & 0.000 & -0.167 & 6.265 & 0,000 \\
$\mathrm{H} 3 \mathrm{~b}:$ age $\rightarrow$ effectiveness & 0.041 & 2.062 & 0.040 & -0.068 & 3.124 & 0,002 \\
$\mathrm{H} 3 \mathrm{c}:$ attractiveness $\rightarrow$ effectiveness & 0.722 & 51.458 & 0.000 & 0.677 & 43.974 & 0,000 \\
$\mathrm{H} 3 \mathrm{~d}:$ age $\rightarrow$ attractiveness $\rightarrow$ effectiveness & 0.079 & 3.955 & 0.000 & -0.113 & 6.219 & 0.000 \\
\hline
\end{tabular}


The hypothesis concerning the relationship between age and latent variables: attractiveness and effectiveness of advertisements (H3 hypothesis) was also confirmed. Both in the case of adapted and standardized advertising, the significance of the tests used was lower than the adopted critical significance level of $p=0.05$. This applies to both direct dependencies (H3a: age $\rightarrow$ attractiveness, H3b: age $\rightarrow$ effectiveness, H3c: attractiveness $\rightarrow$ effectiveness) and the indirect influence of age on the effectiveness of advertisements (H3d: age $\rightarrow$ attractiveness $\rightarrow$ effectiveness). It should be noted that the strength of the influence of age on both latent variables is low, while the influence of advertising attractiveness on its effectiveness is clearly more significant.

As the results show, Polish consumers are critical of the standardization of advertisements and, above all, expect that the advertising communications will be adjusted to local conditions. This confirms the theses discussed in studies conducted in other countries, which show that global advertising appears to be less attractive (Spielman \& Delvert, 2014; Backhaus \& van Doorn, 2007). The second thesis confirmed by the studies is that advertising messages must be adapted to local conditions in order to achieve a higher acceptance index (Melewar \& Vemmervik, 2004).

This generally critical attitude towards global advertising has not changed over the last dozen or so years (Nowacki, 2007a). Despite their reluctant personal attitude towards advertisements created and used by foreign companies, the respondents openly admit that they are better, more professionally prepared and, most importantly, more effective. On the other hand, a positive assessment of the effectiveness of standardized advertising in Poland is consistent with the theses put forward by Okazaki and Taylor (2006) and Zou and Cavusgill (1996), who show that standardized advertising is more effective than adapted advertising.

However, it is difficult to relate the results of the presented research directly to other studies carried out to date using the perspective of demographic analyses. The reason is that, so far, very few researchers have addressed the issue of the perception of standardized and adapted advertising examining variables such as gender and age. The available stud- ies and literature output focus primarily on the importance of the degree of ethnocentrism (Boddewyn et al., 1986; Hite \& Frazer, 1988; Kanso, 1992), the openness of societies (Rajabi et al., 2015), or cultural differences (Zhou et al., 2015).

\section{Conclusions and Limitations}

The presented research findings show how Polish consumers perceive advertisements of foreign companies as well as the strategies applied in them. First of all, the respondents pay attention to some negative aspects of its assessment. As a consequence, they indicate the implications for improving advertising activities. The focus is therefore on the need to adapt the messages to the specific characteristics of the Polish market. Even though standardization appears to have a greater impact on the competitiveness of foreign advertisers, and it contributes to the greater attractiveness and originality of their messages, in respondents' view, the informative value, comprehensibility and persuasiveness as well as adjustment to expectations are assessed as worse and receive lower scores. In order to increase the effectiveness and strength of advertising impact, companies should consider and adapt to the opinions of recipients to a greater extent.

The presented research has some limitations. The basic issue in this case is building an appropriate research tool. The perception of advertising is a subjective phenomenon that cannot be unequivocally quantified. In subsequent studies, more complex ordinal scales, for example, five-point scales, should also be used. This is especially true for predictors that create latent variables. The strength of the factor loadings for some of them proves to be uneven.

Another aspect that deserves attention is the awareness of the concepts related to the standardization and adaptation of advertising among the respondents. Conducting research via the Internet (without the researcher-respondent interaction) makes it impossible to fully control their readability and comprehension. Therefore, the measurement instrument should be extended to include questions to verify the understanding of these terms.

Conducting comparative studies in different national markets appears to be an interesting challenge for further research projects. Such studies would en- 
able the author to identify the similarity of Polish consumers' expectations to those in other countries, thus providing suggestions concerning the possibility of transferring advertising activities from country to country.

\section{References}

Arens, W.F., Schaefer, D.H, \& Weigold, M. (2009). Essentials of contemporary advertising. McGraw-Hill.

Backhaus, K., \& van Doorn, J. (2007). Consumer perceptions of advertising standardization: A crosscountry study of different advertising categories. International Management Review, 3(4), 37-49.

Backhaus, K., Muhlfeld, K., \& van Doorn, J. (2001). Consumer perspectives on standardization in international advertising: a student sample. Journal of Advertising Research, 41(5), 53-61. https://doi. org/10.2501/JAR-41-5-53-61.

Belch, G.E., \& Belch, M.A. (2009). Advertising and promotion. An integrated marketing communications perspective. McGraw-Hill.

Boddewyn, J., Soehl, R., \& Picard, J. (1986). Standardization in international marketing: is Ted Levitt in fact right? Business Horizons, 29(6), 69-75. https:// doi.org/10.1016/0007-6813(86)90040-6.

Burke, M.C., \& Edell J. (1989). The impact of feelings on ad-based affect and cognition. Journal of Marketing Research, 26(1), 69-83. https://doi. org/0.1177/002224378902600106.

Clow, K.E., \& Baack, D. (2010): Integrated advertising, promotion and marketing communications. Pearson Education.

De Mooij, \& M., Hofstede, G. (2002). Convergence and divergence in consumer behavior: Implications for international retailing. Journal of Retailing, 78(1), 61-69. https://doi.org/10.1016/S00224359(01)00067-7

De Mooij, M. (2003). Convergence and divergence in consumer behavior: Implications for global advertising. International Journal of Advertising, 22(2), 183-202. https://doi.org/10.1080/02650487.2003. 11072848 .

De Mooij, M. (2004). Consumer behavior and culture: Consequences for global marketing and advertising. SAGE Publications.

De Mooij, M. (2010). Global marketing and advertising: Understanding cultural paradoxes. SAGE Publications.

De Mooij, M. (2015). Cultural marketing: Maximising business effectiveness in a multicultural world.
Journal of Cultural Marketing Strategy, 1(1), 11-18.

De Mooij, M., \& Hofstede G. (2010). The Hofstede model: Applications to global branding and advertising strategy and research. International Journal of Advertising, 29(1), 85-110. https://doi. org/10.2501/S026504870920104X.

Franke, G., \& Sarstedt, M. (2018). Heuristics versus statistics in discriminant validity testing: A comparison of four procedures. Internet Research, 29(3), 430-447. https://doi.org/10.1108/IntR-122017-0515.

Gudergan, S.P., Ringle, C.M., Wende, S., \& Will, A. (2008). Confirmatory tetrad analysis in PLS path modeling. Journal of Business Research, 61(12), 1238-1249. https://doi.org/10.1016/j. jbusres.2008.01.012.

Hair, J.F., Ringle, C.M., \& Sarstedt, M. (2011). PLSSEM: Indeed a silver bullet. Journal of Marketing Theory and Practice, 19(2), 139_152. https://doi. org/10.2753/MTP1069-6679190202.

Hanna, N., \& Wozniak, R. (2001). Consumer behaviour. An applied approach. Prentice Hall.

Harris, G. (1994). International advertising standardization: What do the multinationals actually standardize? Journal of International Marketing, 2(4), 13-30. https://doi. org/10.1177/1069031X9400200402.

Harris, G., \& Attour, S. (2003). The international advertising practices of multinational companies: A content analysis study. European Journal of Marketing, 37(1/2), 154-168. https://doi. org/10.1108/03090560310454028.

Harvey, M.G. (1993). A model to determine standardization of the advertising process in international markets, Journal of Advertising Research, 33(4), 57-64.

Henseler, J., Ringle, C.M., \& Sarstedt, M. (2015). A new criterion for assessing discriminant validity in variance-based structural equation modeling. Journal of the Academy of Marketing Science, 43(1), 115-135. https://doi.org/10.1007/s11747014-0403-8.

Hite, R., \& Frazer, C. (1988). International advertising strategies of multinational corporations. Journal of Advertising Research, 28(4), 9-17.

Hofstede, G. (2011). Dimensionalizing cultures: The Hofstede model in context. Online Readings in Psychology and Culture, 2(1), 1-26. https://doi. org/10.9707/2307-0919.1014.

Jain, S.C. (1989). Standardization of international marketing strategy: some research hypotheses. Journal of Marketing, 53(1), 70-79. https://doi. 
org $/ 10.2307 / 1251525$.

Kanso, A. (1992). International advertising strategies: Global commitment to local vision. Journal of Advertising Research, 32(1), 10-14.

Kanso, A., \& Nelson, R.A. (2002). Advertising localization overshadows standardization. Journal of Advertising Research, 42(1), 79-89. https://doi. org/10.2501/JAR-42-1-79-89.

Keegan, W.J., \& Green, M.S. 2000. Global marketing. Prentice Hall.

Kirpalani, V.H., Laroche, M., \& Darmon, R.Y. (1988). Role of headquarter control by multinationals in international advertising decisions. International Journal of Advertising, 7(4), 323-333. https://doi. org/10.1080/02650487.1988.11107073.

Kock, N., (2015). Common method bias in PLS-SEM: A full collinearity assessment approach. International Journal of e-Collaboration, 11(4), 1-10. doi: 10.4018/ijec.2015100101.

Kotler, P. (1997). Marketing Management. Prentice Hall.

Latif, K.F., Pérez, A., \& Sahibzada, U.F. (2020). Corporate Social Responsibility (CSR) and customer loyalty in the hotel industry: A cross-country study. International Journal of Hospitality Management, 89, 102565. https://doi.org/10.1016/j. ijhm.2020.102565.

Levitt, T. (1983). Globalization of markets, Harvard Business Review, 61, 92-102.

Levitt, T. (1996). The marketing imagination. Free Press.

Lunenburg, F.C. (2010). Communication: The process, barriers, and improving effectiveness. Schooling, 1(1), 1-11.

MacKenzie, S.B., \& Lutz, R.J. (1989). An empirical examination of the structural antecedents of attitude toward the ad in an advertising pretesting context. Journal of Marketing, 53(2), 48-65. https://doi. org/10.2307/1251413.

Melewar, T.C., \& Vemmervik, C. (2004). International advertising strategy. A review, reassessment and recommendation. Management Decision, 42(7), 863-881. https://doi. org/10.1108/00251740410550934.

Melewar, T.C., Turnbull, S., \& Balabanis, G. (2000). International advertising strategies of multinational enterprises in the Middle East. International Journal of Advertising, 19, 529-547. https://doi.org/10. 1080/02650487.2000.11104819.

Menon, R. (2014). Global or Glocal: The future course for strategy? Global Journal of Finance and Management, 6(5), 427-432.
Moon, B.J., \& Jain S.C. (2002). Consumer processing of foreign advertisements: roles of country-of-origin perceptions, consumer ethnocentrism, and country attitude. International Business Review, No. 11(2), 117-138. https://doi.org/10.1016/S09695931(01)00052-X.

Mueller, B. (1991). Multinational advertising - factors influencing the standardization v. specialized approach. International Marketing Review, 8, 7-18. https://doi.org/10.1108/02651339110003934

Mueller, B. (1992). Standardization vs. specialization: an examination of westernization in Japanese advertising. Journal of Advertising Research, 32(1), 15-24.

Nelson, M., \& Paek, H. (2007). A content analysis of advertising in a global magazine across seven countries: Implications for global advertising strategies. International Marketing Review, 24(1), 64-86. https://doi.org/10.1108/02651330710727196

Nowacki, R. (2007a). Koncepcje działań marketingowych przedsiębiorstw zagranicznych na rynku polskim [Concepts of marketing activities of foreign companies on the Polish market]. Handel Wewnętrzny, 53(1), 19-26.

Nowacki, R. (2007b), Marketing globalisation - Polish market experience. Contemporary Economics, 1(3), 55-70.

Nowacki, R. (2008). Standaryzacja czy indywidualizacja? Dylematy reklamy $w$ czasach globalizacji [Standardization or individualisation? Advertising dilemmas in the times of globalization]. In G. Sobczyk (Ed.), Współczesny marketing - strategie [Contemporary Marketing - Strategies]. PWE, 55-61.

Okazaki, S., \& Taylor, Ch.R., (2006). Towards an understanding advertising standardisation in the European Union: a theoretical framework and research propositions. In: International advertising and communication: current insights and empirical findings. Deutscher Universitäts-Verlag, p. 439-454.

Onkvisit, S., Shaw, J.J. (1990). Global advertising: Revolution or myopia. Journal of International Consumer Marketing, 2(3), 97-112. https://doi. org/10.1300/J046v02n03_06.

Papavassiliou, N., \& Stathakopoulos, V. (1997). Standardization versus adaptation of international advertising strategies: Towards a framework. European Journal of Marketing, 31(7), 504-527. https:// doi.org/10.1108/03090569710176646

Park, C.W., \& Young, S.M. (1986). Consumer response to television commercials: the impact of involve- 
ment and background music on brand attitude formation. Journal of Marketing Research, No. 23, 1124. https://doi.org/10.1177/002224378602300102.

Rajabi, M., Dens, N., \& De Pelsmacker, P. (2015). Advertising adaptation versus standardization effectiveness in open and closed markets. Advances in Advertising Research, 5, 177-190.

Sanayei, A., Javadi, M.H.M., \& Baluchianzade, R. (2012). Determining the effect of ethics on advertising effectiveness with Mellat Bank customer. Interdisciplinary Journal Of Contemporary Research In Business, 3(9), 96-104.

Schmidt, K. (2016). Standardization of International Advertising Strategies: A Content Analysis of Pantene Pro-V. Elon Journal of Undergraduate Research in Communications, 7(1), 79-87. Retrieved from: http://www.inquiriesjournal.com/ a?id=1470 (15.03.2021).

Seitz, V.A. \& Johar, J.S. (1993). Advertising practices for self-image projective products in the New Europe. Journal of Consumer Marketing, 10(4), 1526. https://doi.org/10.1108/07363769310054277.

Shoham, A. (1995). Global marketing standardization. Journal of Global Marketing, 9(1/2), 91-117. https://doi.org/10.1300/J042v09n01_05.

Shoham, A. (1999). Bounded rationality, planning, standardization of international strategy, and export performance: a structural model examination. Journal of International Marketing, 7(2), 24-50. https://doi.org/10.1177/1069031X9900700203.

Spielman, N., \& Delvert, M., (2014). Adapted or standardized copy: Is non-cultural English the answer? Journal of Business Research, 67(4), 434440. http://doi.org/10.1016/j.jbusres.2013.03.029.

Synodinos, N., Keown, C., \& Jacobs, L. (1989). Traditional advertising practices: a survey of leading brand advertisers. Journal of Advertising Research, 29(3), 43-50.

Toyne, B., \& Walters, P.G.P. 1993. Global Marketing Management. Prentice Hall.

Wang, X. \& Yang, Z. (2011). Standardization or adaptation in international advertising strategies: The roles of brand personality and country-of-origin image. Asian Journal of Business Research, 1(2), 25-36. https://doi.org/10.14707/ajbr.110009.

Zhou, L., Poon, P., \& Wang, H. (2015). Consumers' reactions to global versus local advertising appeals: A test of culturally incongruent images in China. Journal of Business Research, 68(3), 561-568. https://doi.org/10.1016/j.jbusres.2014.09.006.

Zou S., Andrus, D.M., \& Norvell, D.W. (1997). Standardization of international marketing strategy by firms from a developing country. International Marketing Review, 14(2), 107-123. https://doi. org/10.1108/02651339710170203.

Zou, S., \& Cavusgil, S.T. (1996). Global strategy: A review and an integrated conceptual framework. European Journal of Marketing, 30(1), 52-70. http:// doi.org/10.1108/03090569610105799. 